\title{
Photocatalytic degradation of Direct Brown RN dye in the presence of $\mathrm{ZnO}$ nanoparticles
}

\author{
A. S. M. A. Islam, T. Ferdous *, A. K. Das, M. M. Karim and S. M. Masum \\ Department of Applied Chemistry and Chemical Engineering, University of Dhaka, Dhaka 1000, Bangladesh
}

\begin{abstract}
The $\mathrm{ZnO}$ nanoparticle was prepared by using $\mathrm{Zn}\left(\mathrm{NO}_{3}\right)_{2} \cdot 6 \mathrm{H}_{2} \mathrm{O}$ and $\mathrm{NaOH}$ under optimum reaction conditions and the prepared nanoparticle was characterized by UV-visible spectroscopy, X-ray diffraction (XRD), Fourier transform infrared spectroscopy (FT-IR), energy dispersion X-ray spectroscopy (EDX) and scanning electron microscopy (SEM). The sunlight irradiated photocatalytic degradation of Direct Brown RN dye was studied using $\mathrm{ZnO}$ nanoparticle. The results of this investigation revealed that in the presence of sunlight, catalyst load of $0.5 \mathrm{~g} \cdot \mathrm{L}^{-1}$ and time of contact of $40 \mathrm{~min}, \mathrm{ZnO}$ nanoparticle showed substantial capability of destroying Direct Brown RN dye from solution. An actual leather effluent containing Brown $\mathrm{RN}$ as a major constituent along with other dyes and dyeing auxiliaries was treated using $\mathrm{ZnO}$ and the reduction in the chemical oxygen demand (COD) of the treated effluent revealed almost complete destruction of the organic molecules along with color removal.
\end{abstract}

Keywords: ZnO; Nanoparticles; Photodegradation; Direct Brown RN dye

\section{Introduction}

Dyes can easily contaminate the water bodies through their discharge from the industries. Non-biodegradable nature of most of the dyes which result in perturbation in aquatic diversity by blocking the passage of sunlight through the water represents serious problems to the environment. It is reported that less than $1 \mathrm{ppm}$ of dye content causes obvious water coloration (Al-Degs et al., 2000). There are more than 100,000 commercially available dyes and globally over $7 \times 10^{5}$ tons of dye is produced in a year and $15 \%$ of which is lost during the dyeing process (Martinez-Huitle and Brillas, 2009). Leather processing and leather products manufacturing are important export-orientated industries in Bangladesh. The full flourishing of this sector is significant for the country's economy. Most of these processing plants have no effluent treatment plant. They directly dispose untreated colored and toxic effluent into the nearby rivers and other waterways, thereby causing serious environmental pollution.

Development of technological systems for the removal of organic dyes has recently been on the rise. These include physical methods such as adsorption (McKay, 1982, Chatterjee et al., 2010), coagulation (Zargar et al., 2009), biodegradation (Moore et al., 1989) and chemical methods such as chlorination, ozonation etc (Slokar and Le Marechal 1998). Physical and biological methods do not destroy the pollutants but simply transfer the pollutant to another phase which again creates disposal problem. On the other hand chemical methods have the disadvantages of using strong oxidants like chlorine and ozone which are themselves hazardous in nature. However, photocatalytic technology as an advanced oxidation process (AOP) promotes the degradation of pollutants through producing hydroxyl radicals $(\cdot \mathrm{OH})$ from water molecules as strong oxidizing agent which eventually converts the organic dye molecules into $\mathrm{CO}_{2}$ gas.

The most important reason for choosing $\mathrm{ZnO}$ as photocatalyst is its ability to show photo catalytic efficiency in both UV and visible range of light i.e. direct sunlight can be used as light source. The focus of the present work is to synthesize $\mathrm{ZnO}$ nanoparticles and use it in the photocatalytic degradation of Direct Brown RN (disodium4-[4-[4-[2,4-diamino-5-(4-sulfonatophenyl) diazenylphenyl]diazenylphenyl] phenyl] diazenyl-2hydroxybenzoate, Figure 1.), using sunlight irradiation.

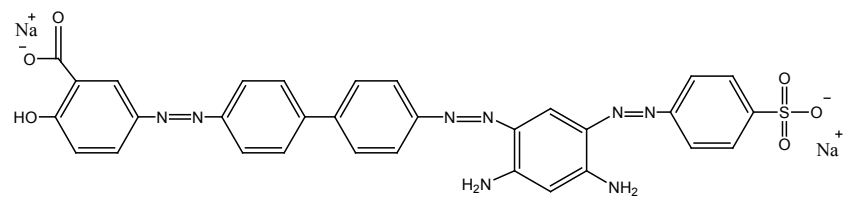

Fig. 1. Chemical structure of Direct Brown RN.

*Corresponding author: E-mail: taslima_ferdous@yahoo.com 


\section{Materials and methods}

\section{Materials}

Zinc nitrate hexahydrate $\left[\mathrm{Zn}\left(\mathrm{NO}_{3}\right)_{2} \cdot 6 \mathrm{H}_{2} \mathrm{O}\right]$ was purchased from JHD group, Guandang, China. Sodium hydroxide $(\mathrm{NaOH})$ was obtained from NEN Tech. Ltd. Brixworth, UK. Direct Brown RN dye (molecular formula: $\mathrm{C}_{31} \mathrm{H}_{22} \mathrm{~N}_{8} \mathrm{Na}_{2} \mathrm{O}_{6} \mathrm{~S}$, formula weight: 680.615, C.I. No: 30045) was supplied by Apex Tannery Ltd, Hazaribag, Bangladesh. Stock solution of Direct Brown RN dye $\left(2.5 \times 10^{-5} \mathrm{~mol} \cdot \mathrm{L}^{-1}\right)$ was prepared daily by dissolving appropriate amount of dye solid in deionized water. All experiments were performed with analytical grade reagents and directly used without further purification. Doubly deionized water was used throughout.

\section{Apparatus}

Ultraviolate visible (UV-vis) spectral measurements were performed on a UV-1700 (Shimadzu, Japan) spectrophotometer. $\mathrm{ZnO}$ crystal structures were characterized by X-ray diffractometry (XRD) using a D8 ADVANCE diffractometer (Bruker, Germany). The morphology and chemical composition of the $\mathrm{ZnO}$ nanoparticles were observed by means of JSM-6490 scanning electron microscopy (SEM) and EDX analysis (JEOL, USA). FTIR spectra were recorded on a Prestidge-21 IR (Shimadzu, Japan) spectrophotometer from samples in $\mathrm{KBr}$ pellets.

\section{Nanoparticle preparation}

$\mathrm{ZnO}$ nanoparticles were prepared following the procedure described elsewhere (Kawano and Imai, 2008). A $0.2 \mathrm{M}$ solution of zinc nitrate and a $4.0 \mathrm{M}$ alkali solution of sodium hydroxide were separately prepared by dissolving zinc nitrate hexahydrate $\mathrm{Zn}\left(\mathrm{NO}_{3}\right)_{2} \cdot 6 \mathrm{H}_{2} \mathrm{O}$ and $\mathrm{NaOH}$, respectively, in deionized water. To prepare $\mathrm{ZnO}$ nanoparticles, $2 \mathrm{~mL}$ of the alkali solution $(4.0 \mathrm{M} \mathrm{NaOH})$ was dropped at an approximate rate of $0.5 \mathrm{~mL} / \mathrm{min}$ into a $20 \mathrm{~mL}$ aqueous solution of $0.2 \mathrm{M} \mathrm{Zn}\left(\mathrm{NO}_{3}\right)_{2} \cdot 6 \mathrm{H}_{2} \mathrm{O}$ with stirring. The final $\mathrm{pH}$ of the mixture was fixed at 13 as highly basic conditions are conducive to the direct preparation of $\mathrm{ZnO}$ crystals (Nejati et al., 2011). The products obtained by centrifugation were washed with deionized water and dried at $60^{\circ} \mathrm{C}$ in air. Prepared $\mathrm{ZnO}$ was then characterized by UV, FTIR, EDX, XRD and SEM analysis.

Decolorization Efficiency $(\%)=\frac{\text { Co-C }}{\mathrm{C} 0} \times 100$

\section{Photocatalytic Degradation of dye}

In photocatalytic experiments, Direct Brown $\mathrm{RN}$ dye solution $(50 \mathrm{~mL})$ and the catalyst $(\mathrm{ZnO})$, were taken in a beaker and exposed to sunlight for upto $40 \mathrm{~min}$. Dye samples of about 2-3 mL were taken out at a regular intervals of $10 \mathrm{~min}$ from the test solution, centrifuged for 4-5 $\mathrm{min}$ at 950-1000 $\mathrm{rpm}$ and their absorbance were recorded using a spectrophotometer. The percentage decolorization efficiency (\%) was calculated from the equation given below

where $\mathrm{C}_{0}$ is the initial concentration of dye and $\mathrm{C}$ is the concentration of dye after photo irradiation at varying reaction time (expressed in $\left.\mathrm{mol} \cdot \mathrm{L}^{-1}\right)$.

\section{Effluent Treatment}

Colored effluent containing Direct Brown RN dye as a major constituent along with other dyes and dyeing auxiliaries were collected from the discharge line of a local leather processing plant (Apex Tannery Ltd, Hazaribag). The effluent was treated using the prepared $\mathrm{ZnO}$ nano under varying conditions. The same photocatalytic experimental set up, as used for the dye solution, was employed here for effluent treatment. The chemical oxygen demand (COD) of the untreated and treated (with $\mathrm{ZnO}$ nanoparticles) effluents was determined using $\mathrm{KMnO}_{4}$ oxidation method (Clesceri et al., 1998).

\section{Results and discussion}

\section{Analysis of $\mathrm{ZnO}$ Nanoparticle}

A characteristics peak for $\mathrm{ZnO}$ nanoparticle was found at $350 \mathrm{~nm}$ wavelength in UV analysis (Figure $2 \mathrm{a}$ ). Figure $2 \mathrm{~b}$ shows the FT-IR spectra of the synthesized $\mathrm{ZnO}$ particles. The IR spectra of samples of $\mathrm{ZnO}$ particles are generally influenced by the particle size and morphology (Nejati et al., 2011). The peaks at wavenumber 671 and $559 \mathrm{~cm}^{-1}$ are related to the stretching vibrations of $\mathrm{Zn}-\mathrm{O}$ bonds. The peak at $3414 \mathrm{~cm}^{-1}$ indicates the presence of $-\mathrm{OH}$ residue, probably due to atmospheric moisture (Nejati et al., 2011). The comparison of the synthesized $\mathrm{ZnO}$ peak in various plane with the JCPDS (Joint Committee on Powder Diffraction Standards) data shows presence of peak in similar position (Figure 2c). In case of synthesized $\mathrm{ZnO}$, broad peaks of higher intensity affirm the smaller particle size (Nejati et al., 2011, Kale et al., 2009). The crystallite size was calculated using Scherrer's formula (Scherrer, 1918) and found to be $18.79 \mathrm{~nm}$. The SEM (Figure 2d) shows that the particles are uniform in shape and well dispersed with particle size below $200 \mathrm{~nm}$. The chemical stoichiometry of $\mathrm{ZnO}$ nano particle was investigated with EDX (Figure 2e), which affirmed an atomic ratio of $\mathrm{Zn}: \mathrm{O}$ $=48.02: 51.98 \approx 1: 1$. No characteristic peaks of any other phase of $\mathrm{ZnO}$ or of any impurity were observed in XRD or 


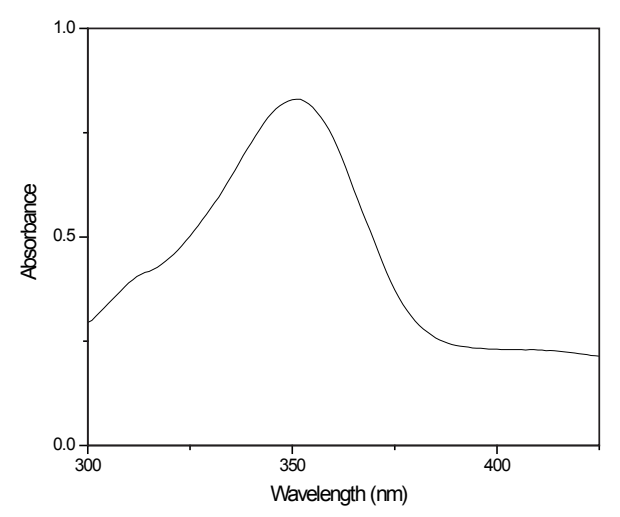

a.

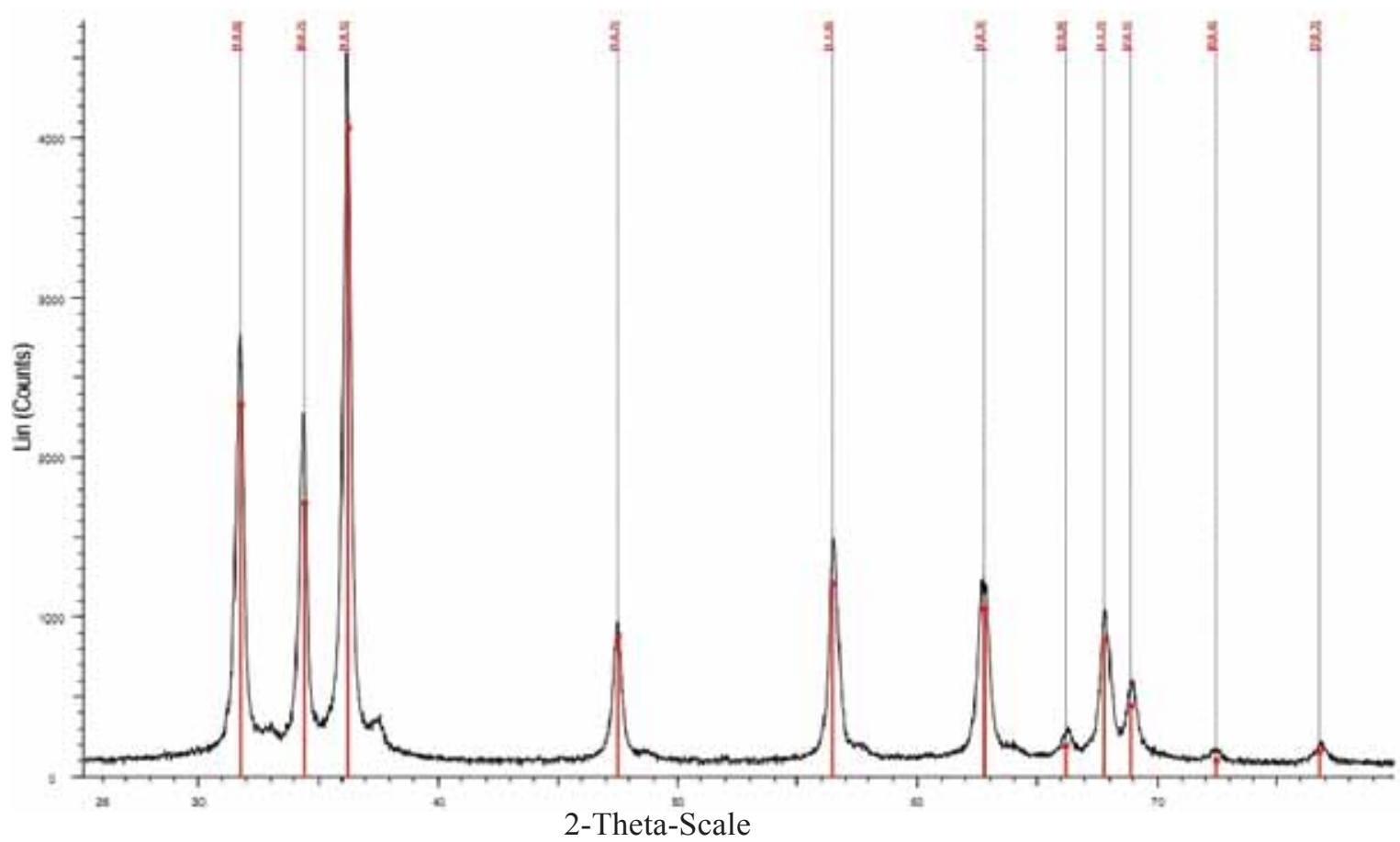

c.

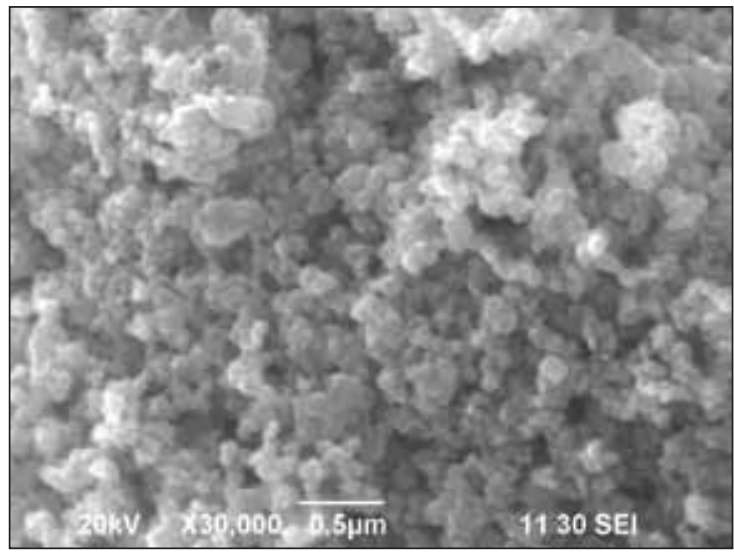

d.

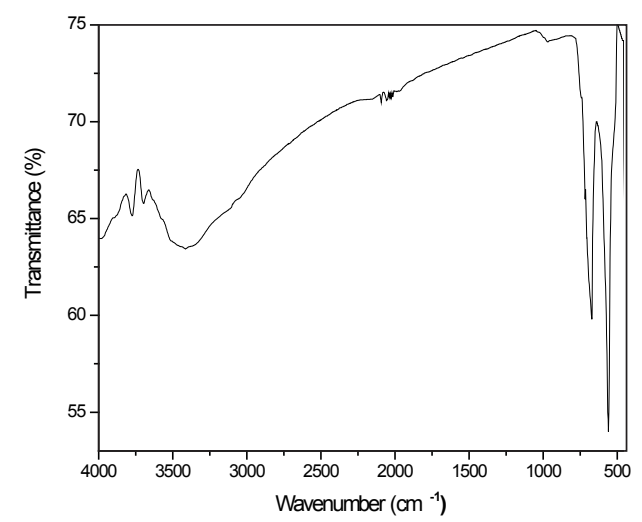

b.

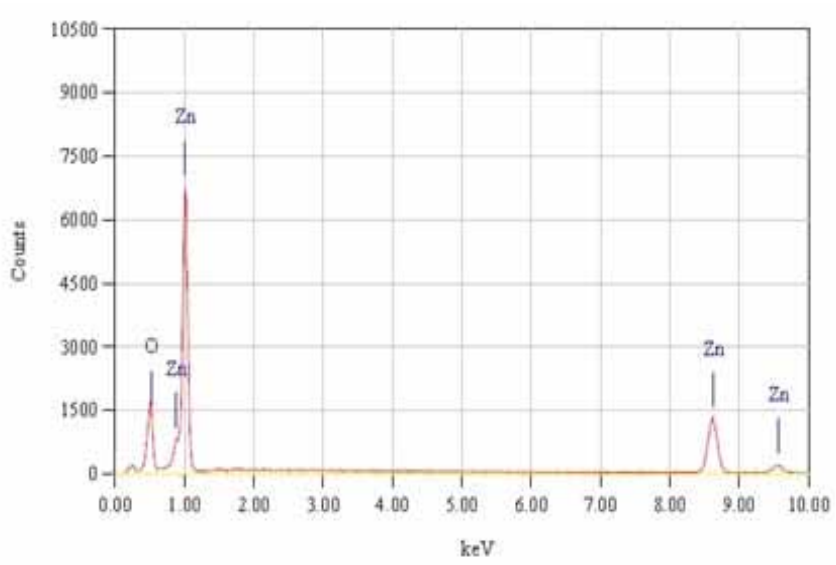

e.

Fig. 2. Characteristics of prepared ZnO nanoparticle. a. UV-Visible; b. FT-IR; c. XRD d. SEM and e.EDX spectrum. 
EDX analysis. This result indicates the high purity of the $\mathrm{ZnO}$ nanoparticles.

\section{Photodegradation studies}

The UV spectral characteristics of the Direct Brown RN dye at different time intervals are shown in Figure 3. The dye was irradiated under sunlight at a 10 minutes interval for 40 minutes to observe if there is any degradation effect. The absorption peak gradually decreases as the

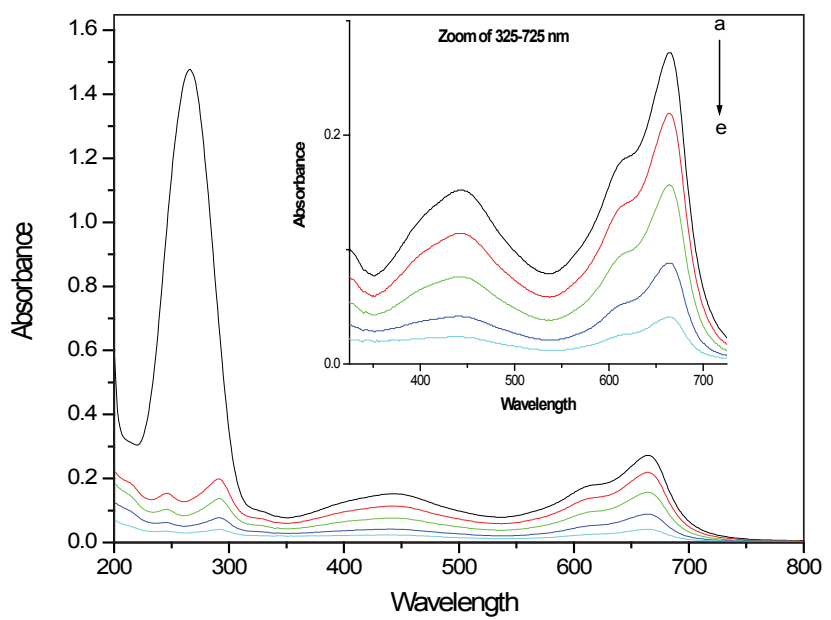

Fig. 3. UV spectra of Direct Brown RN dye at regular intervals $(\mathrm{a} \rightarrow \mathrm{e})$ after applying $\mathrm{ZnO}$ nanoparticles. ( INSET showing zoom from wavelength 325 to $725 \mathrm{~nm}$ ). Conditions: Dye concentration, 2×10-5 mol.L-1; Catalyst loading, $0.5 \mathrm{~g} \cdot \mathrm{L}-1$; Degradation time, 0, 10, 20, 30 and $40 \mathrm{~min}$.

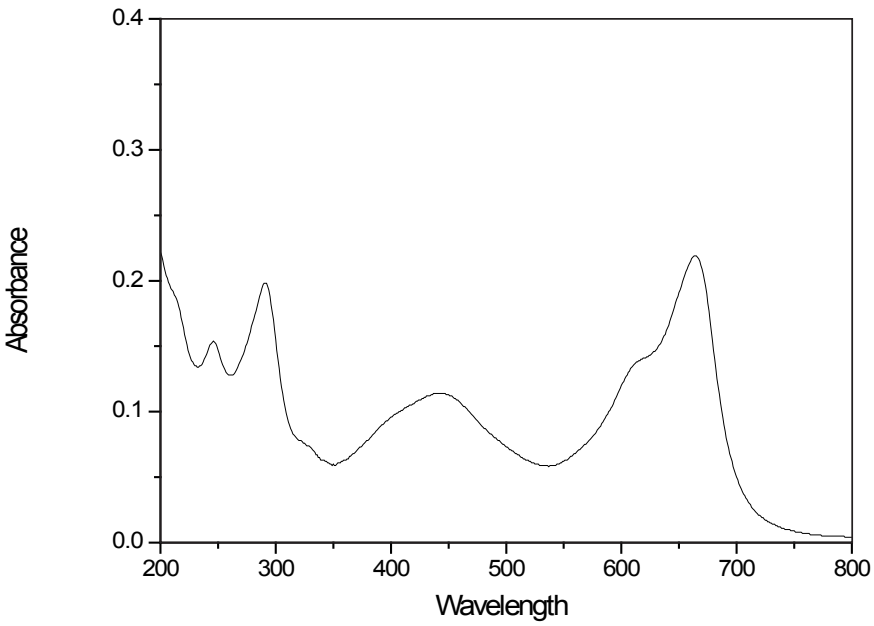

Fig. 4. UV spectra of Direct Brown RN dye showing no change after exposure to sunlight for 40 mins in the absence of $\mathrm{ZnO}$ nanoparticles. concentration decreased. This is in agreement with the knowledge that the amount of organic compound contained is less for solution with lower concentration. The decreasing of the absorption peak at $440 \mathrm{~nm}$ indicates that the decomposition of organic compound in the solution has taken place. To check the significance of the catalytic effect of $\mathrm{ZnO}$ nanoparticles, the dye was irradiated under sunlight without the presence of $\mathrm{ZnO}$. The result showed that no degradation of the dye took place in the absence of $\mathrm{ZnO}$ nanoparticles after 40 mins of sunlight exposure (Figure 4). The effect of initial dye concentration on the decolorization efficiency was studied by varying the concentration from $5 \times 10^{-5} \mathrm{~mol} \cdot \mathrm{L}^{-1}$ to $2.5 \times 10^{-6} \mathrm{~mol} \cdot \mathrm{L}^{-1}$ and keeping $\mathrm{ZnO}\left(0.5 \mathrm{~g} \cdot \mathrm{L}^{-1}\right)$ as constant. The results are presented in Figure 5 . It is seen that the decolorization efficiency of Direct Brown $\mathrm{RN}$ dye decreases with the increase of initial dye concentrations. This follows from the fact that the active surface on the

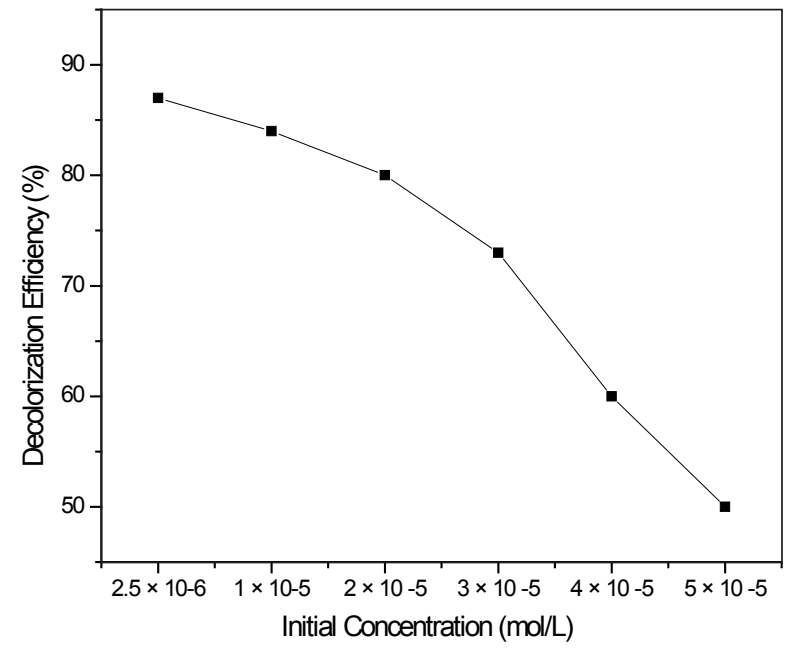

Fig. 5. Effect of initial concentration of Direct Brown RN dye on decolorization efficiency. Conditions: Catalyst loading, $0.5 \mathrm{~g} \cdot \mathrm{L}-1$; degradation time, $40 \mathrm{~min}$.

\begin{tabular}{rcr}
\hline $\begin{array}{c}\text { Direct } \begin{array}{c}\text { Brown } \\
\left(\mathrm{mol} \cdot \mathrm{L}^{-1}\right)\end{array} \\
\mathrm{RN}\end{array}$ & $K\left(\mathrm{~m}^{-1}\right)\left(10^{-2}\right)$ & $t 1 / 2 \mathrm{~min}$ \\
\hline $5 \times 10^{-5}$ & 2.41 & 27.12 \\
$4 \times 10^{-5}$ & 3.53 & 18.50 \\
$3 \times 10^{-5}$ & 4.8 & 14.22 \\
$2 \times 10^{-5}$ & 5.06 & 13.20 \\
$1 \times 10^{-5}$ & 5.52 & 12.79 \\
$2.5 \times 10^{-6}$ & 5.79 & 11.55 \\
\hline
\end{tabular}


catalyst available for reaction is very crucial for the degradation to take place. As the dye concentration is increased and the catalyst amount is kept constant, this results in fewer active sites for the reaction. The rate constant $(\mathrm{K})$ and $t_{1 / 2}$ values for experimental values of different concentrations of Direct Brown $\mathrm{RN}$ dye are summarized in Table 1. It is observed that as the initial concentration decreases the rate constant increases and half life decreases. This means that the reaction became faster and more feasible with the decrease in concentration.

Figure 6 shows the variation of decolorization efficiency with the amount of catalyst loaded. The decolorization efficiency is found to increase when catalyst load was increased upto $0.50 \mathrm{~g} \cdot \mathrm{L}^{-1}$ and then it decreases. The reduction in the decolorization efficiency when the catalyst amount is increased above $0.50 \mathrm{~g} \cdot \mathrm{L}^{-1}$ may be due to light scattering and reduction in light penetration through the solution. With a higher catalyst loading the deactivation of activated molecules by collision with ground state molecules dominates the reaction, thus reducing the rate of reaction (Neppolian et al. 2001).

The $\mathrm{ZnO}$ used in the photocatalytic treatment was centrifuged, dried at $60^{\circ} \mathrm{C}$ in an oven and it was reused as

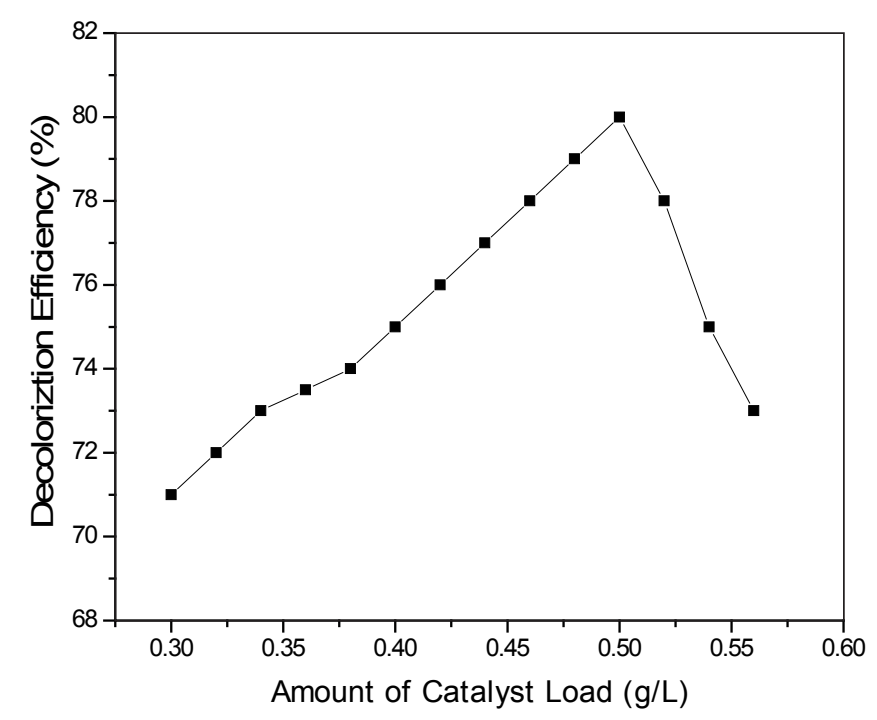

Fig. 6. Effect of different amount of catalyst load on decolorization efficiency. Conditions: Dye concentration, $2 \times 10-5 \mathrm{~mol} \cdot \mathrm{L}-1$; degradation time, $40 \mathrm{~min}$.

such in the succeeding photocatalytic experiments. The efficiency of photocatalytic degradation of dye solution using this regenerated $\mathrm{ZnO}$ was observed to be nearly the same.

\section{Effluent treatment}

A sample of colored effluent from the leather processing industry which uses Direct Brown RN dye and other chemicals was subjected to the photocatalytic degradation of dye molecules using $\mathrm{ZnO}$ nanoparticle. The degradation efficiency of the effluent was evaluated in this study through the COD of the treated and untreated effluent. Thus the degradation efficiency of the effluent under the given experimental conditions was obtained as $72.86 \%$.

\section{Conclusion}

$\mathrm{ZnO}$ nanoparticle was successfully prepared with a cheap, easy to operate and reproducible procedure and the physicochemical properties of $\mathrm{ZnO}$ nano crystals were analyzed. The prepared $\mathrm{ZnO}$ nanoparticle photocatalyst effectively treated Direct Brown RN dye leading to its degradation. The developed method was successful in reducing COD values of tannery effluent. Thus, a simple and environmentally benign photocatalytic degradation method has been described for removal of Direct Brown $\mathrm{RN}$, a common dye used in tannery industries of Bangladesh.

\section{Acknowledgement}

This research was funded by the Ministry of Science and Technology, Bangladesh and supported by the Department of Applied Chemistry and Chemical Engineering, University of Dhaka.

\section{References}

Al-Degs Y, Khraisheh MAM, Allen SJ and Ahmad MN (2000), Effect of carbon surface chemistry on the removal of reactive dyes from textile effluent, Water Res. 34: 927-935.

Clesceri LS, Greenberg AE and Eaton AD, eds. (1998), Standard Methods for the Examination of Water and Wastewater, $20^{\text {th }}$ Ed. (American Public Health Association, New York) pp106-110.

Chatterjee D, Patnam VR, Sikdar A and Moulik SK (2010), Removal of Some Common Textile Dyes from Aqueous Solution Using Fly Ash, J. Chem. Eng. Data 55: 5653-5657.

Kale SN, Kitture R, Koppikar SJ, Ghanekar RK and Patil SI (2009), Role of ZnO Bulk and Nanopowders in Photocatalytic Decolorisation of Textile Industrial Dyes, In: INIS collection, International Atomic Energy Agency (IAEA) 43: 1-13. 
Kawano T and Imai H (2008), A simple preparation technique for shape-controlled zinc oxide nanoparticles: Formation of narrow size-distributed nanorods using seeds in aqueous solutions, Colloids Surface A. 319: 130-135.

Moore AT, Vira A and Fogel S (1989), Biodegradation of trans-1,2-dichloroethylene by methane-utilizing bacteria in an aquifer simulator, Environ Sci Technol 23: pp. 403.

McKay G (1982), Adsorption of dyestuffs from aqueous solutions with activated carbon I: Equilibrium and batch contact-time studies, J. Chem. Technol. Biotechnol. 32: 759-772.

Martinez-Huitle CA and Brillas E (2009), Decontamination of wastewaters containing synthetic organic dyes by electrochemical methods: A general review, Appl. Catal.B: Environ. 87: 105-145.

Nejati K, Rezvani Z and Pakizevand R (2011), Synthesis of $\mathrm{ZnO}$ Nanoparticles and Investigation of the Ionic Template Effect on Their Size and Shape, Int. Nano Lett. 1: 75-81.
Neppolian B, Sakthivel S, Banumathi A, Palanichamy M and Murugesan V (2001), ZnO-photoassisted degradation of textile dye using solar energy, Indian $J$. Chem. Technol. 8: 36-40

Scherrer P, (1918), Bestimmung der Grösse und der Inneren Struktur von Kolloidteilchen Mittels Röntgenstrahlen, Nachrichten von der Gesellschaft der Wissenschaften, Göttingen, MathematischPhysikalischeKlasse 2: 98-100.

Slokar YM and Le Marechal AM (1998), Methods of decoloration of textile wastewaters, Dyes Pigments 37: 335-356.

Zargar B, Parham H and Hatamie A (2009), Fast removal and recovery of amaranth by modified iron oxide magnetic nanoparticles, Chemosphere 76: 554-557.

Received: 06 November 2014; Revised: 05 February 2015; Accepted: 24 March 2015. 